\title{
Hacia una historia global de la sexualidad en España
}

\section{Towards a global history of sexuality in Spain}

\author{
Marisa A. Miranda \\ Pesquisadora independente do Consejo Nacional de Investigaciones Científicas y Técnicas. \\ mmiranda2804@gmail.com
}

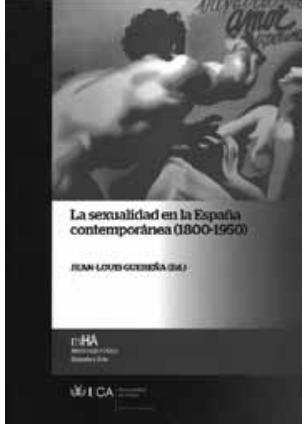

GUEREÑA, Jean-Louis (Ed.). La sexualidad en la España contemporánea (1800-1950). Cádiz: Universidad de Cádiz. 2011. 273p.
$\mathrm{E}$ brillante texto que aquí comentamos logra cumplir con creces su cometido de ofrecer al lector una panorámica diversificada de las principales ramas por donde transcurren - y deben transcurrir - las exploraciones en perspectiva histórica sobre la sexualidad en la España de los siglos XIX y XX. La cuidada edición de Jean-Louis Guereña, unida a la excelencia de los trabajos allí agrupados con significativa coherencia, permiten una visión de conjunto de la problemática en cuestión, que nos anticipa Jean-Louis ya desde el inicio de su capítulo introductorio: ¿Es la sexualidad objeto de historia? A partir de allí, se advierte al lector páginas más adelante, que la historia social de la sexualidad conduce a una historia global, donde se intersectan e interrelacionan prácticas, discursos y representaciones; y que también involucra, claro está, a una historia cultural de la sexualidad ya que, como remarca el editor, "nuestra percepción de la sexualidad es totalmente cultural".

El capítulo siguiente exhuma la campaña médica antimasturbatoria en España durante el siglo XIX, para la cual el calificativo empleado ("médica") no constituye un dato menor y, cuya entidad historiográfica, es muy bien enfatizada por Francisco Vázquez García y José Benito Seoane, sus autores. En efecto, el acto masturbatorio quedaría impregnado, al menos desde la publicación L'onanisme ${ }^{1}$ (1760), de un tufillo patológico, cercano al que también, ya en el siglo XX, tiñera con particular crudeza a la homosexualidad, a la prostitución y, en general, a las "sexualidades anormales", es decir, a aquellas que escapan a la norma. Una norma en cuyo dictado los higienistas decimonónicos ocuparían un lugar protagónico. En este contexto, Vázquez García y Seoane consideran esencial (opinión que compartimos) alejarse del mero plano descriptivo, el de la historia social, de las ideas o de las mentalidades, para examinar el tema desde una historia o genealogía de las "técnicas de gobierno", en sentido foucaultiano; de donde advierten, con indudable atino, que esta perspectiva permite nuevos tipos de análisis y problematización. 
Luego, Jean-Louis Guereña se encarga de historizar, desde las prácticas, al preservativo masculino en la España contemporánea, interrogándose sobre la entidad y presencia efectiva que tuviera en sus sendas funciones, es decir, como dispositivo antivenéreo y como método anticonceptivo. Al respecto, no nos debe pasar inadvertido (y, claro está, tampoco le pasa inadvertido al autor) el rol fundamental del condón en la evidente disociación - tan combatida por la moral católica - entre sexualidad y reproducción. Destaca, al respecto, la "clandestinidad" a la que fueron asociados los preservativos hasta la primera mitad del siglo XX, más vinculados al rol de impedir el peligro venéreo atribuido al encuentro sexual en ambientes prostibularios, que al papel como método para prevenir embarazos no deseados.

Rafael Alcaide González estudia, en el capítulo cuarto, la reglamentación de la prostitución en la Barcelona de la Restauración (1870-1890), y Ramón Castejón Bolea analiza, en el siguiente, los debates sobre la prevención individual de las enfermedades venéreas durante el primer tercio del siglo XX español. Ambos aportes meritan, a mi entender, un comentario en conjunto ya que es bien conocida la complementariedad entre prostitución y enfermedad venérea que impregnara todo discurso sobre la sexualidad en Occidente. En este tema, resultaba clave la educación higiénica, que, como es sabido, oscilaba entre propuestas de abstinencia sexual hasta otras que, sin impedir el coito, enseñaba la profilaxis física y química. No obstante, la cuestión era excedentaria de la salud individual, circunstancia correctamente advertida en el corpus analizado. En efecto, la profilaxis antivenérea estuvo por entonces dotada de un alto componente biopolítico vinculado a la preservación y mejora de la raza, que, instalado desde finales del siglo XIX, llegaría a su cenit durante el XX.

En su capítulo, Raquel Álvarez Peláez centra la atención en la literatura sobre el sexo en España durante las primeras décadas del siglo XX. En ese marco, encara un tema que, dicho sea de paso, atraviesa explícita o implícitamente a todo el libro: el cruce entre sexualidad, moralidad y medicina; adentrándose en la exégesis de diversos textos de divulgación sexual como los de Justo Ma . Escalante, Ángel Martín de Lucenay, Antonio San de Velilla y Octavio Pladeur. La autora nos señala la coexistencia en España, durante los años veinte y treinta del siglo pasado, de una abundante y seria literatura preocupada por la educación sexual y los conflictos morales involucrados con una producción textual más cercana a la divulgación de la sexualidad hasta llegar, en ocasiones, a la pornografía.

El análisis de Raquel Álvarez Peláez se integra adecuadamente, entonces, al tratamiento realizado por Richard Cleminson, quien profundiza en la obra sexológica del Dr. Martín de Lucenay deteniéndose en la transmisión del conocimiento científico y su recepción popular en España a comienzos del siglo XX. En este sentido, nos permitimos recordar aquí la distinción de las lógicas de recepción realizadas por Glick y Henderson (1999), en tética, antitética, correctiva y extensional; lógicas que, a nuestro entender, resultan por demás adecuadas para una hermenéutica del capítulo en cuestión.

Las páginas escritas por Mercedes del Cura y Rafael Huertas se detienen en la evaluación de las aportaciones del psicoanálisis a la pedagogía sexual durante un período clave de la historia contemporánea de España: el primer tercio del siglo XX. Allí, ponen en diálogo a tres entidades sustanciales en ese contexto, como lo fueron educación, medicina y reforma sexual, prestándole una imprescindible atención a la figura de Ángel Garma y su postura crítica a la "aclaración de la sexualidad" de los pedagogos alemanes. 
Por otra parte, Marie-Aline Barrachina, acercándose a una necesaria perspectiva de género, examina la maternidad, feminidad y sexualidad en las Primeras Jornadas Eugénicas españolas, sin desconocer el derrotero seguido hasta la efectiva realización de este encuentro en la primavera de 1933. Como es sabido, en esos momentos, una de las problemáticas fundamentales que signaba aquellos términos era si la mujer también podía permitirse el goce sexual y, más aún, si tenía "autorización" para un placer independiente de "su" función procreativa. Así, el latente reconocimiento de la igualdad de derechos (no sólo reproductivos, sino, más aún, del derecho a la intimidad y al placer) se vería fortalecido por las propuestas de "maternidad consciente" y de birth control, sostenidas desde un neto progresismo de sesgo eugenésico, desactivado luego de la Guerra Civil.

Precisamente este período, es decir, el de la primera década del franquismo, ocupa la mirada del último capítulo del libro, escrito por Anne-Gaëlle Regueillet. Focalizando en el noviazgo, la autora plantea, en realidad, el castigo a las transgresiones sexuales no ya cometidas entre personas del mismo sexo, sino por heterosexuales. Y ahora cabe enfatizar, de nuevo, que la "sanción" al apartamiento de la norma operaba, entonces, con cierta independencia respecto al carácter homo o heterosexual del vínculo. De ahí que, el mandato social de virginidad en la mujer (decente), unido a la exigencia de experiencia heterosexual en el hombre antes de contraer matrimonio, nos habla, en definitiva, de un concepto fundamental para el abordaje historiográfico de la sexualidad y que resulta trascendente a las fronteras españolas: la consolidación de un corpus de pensamiento afirmado en la existencia de jerarquías de género traducidas en la imposición de conductas y en el sojuzgamiento del placer femenino.

Para concluir, consideramos que la atinada calificación de "mirón" que hace Guereña del historiador, en un contexto en el cual nada de lo humano (entre lo que, de más está decirlo, se encuentra la sexualidad) le resulta extraño, no implica caracterizar los trabajos que conforman al texto como un producto voyeurista, de contemplación pasiva a través de un resquicio, de una pulsión por lo oculto y lo vedado. Por el contrario, esta obra - imprescindible - involucra un compromiso intelectual y ético, del editor y de los autores de los diversos capítulos que lo componen, en dar visibilidad a parte de una "otredad" imputable por regla al que escapa (o intenta escapar) a la norma. Otredad que, en definitiva, no es más que una percepción de nosotros mismos.

En este marco, corresponde relativizar la aclaración - no desprovista de evidente humildad - que se realiza en las páginas iniciales respecto a que no se pretende cubrir en el libro un campo aún inexplorado como es el de la historia global de la sexualidad. Sostenemos, pues, que La sexualidad en la España contemporánea (1800-1950) constituye un destacado aporte en tal sentido.

\section{NOTA} ${ }^{1}$ A partir de este texto, reeditado hace una década en España (Tissot, 2003), ya desde el siglo XVIII la
criminalización del acto masturbatorio fue sustituida por su patologización. 


\section{REFERENCIAS}

GLICK, Thomas; HENDERSON, Mark.

Las recepciones científicas y populares de Darwin, Freud y Einstein: hacia una historia analítica de la difusión de las ideas científicas. In: Glick, Thomas; Ruiz, Rosaura; Puig-Samper, Miguel Ángel (Ed.). El darwinismo en España e
Iberoamérica. Madrid: Unam; CSIC; Doce Calles, p.289-297. 1999.

TISSOT, Samuel-Auguste.

El onanismo. Madrid: Asociación Española de Neuropsiquiatría. 2003.

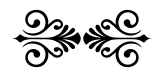

